\title{
Los Derechos Humanos de las mujeres en el marco de protección del Derecho Internacional: un repaso por la convención sobre todas las formas de discriminación contra la mujer
}

Krúpskaya Rosa Luz Ugarte Boluarte* http://dx.doi.org/10.21503/lex.v9i8.394

* Abogada UNSAAC, con Maestría en Derecho con mención en Política Jurisdiccional por la Pontificia Universidad Católica del Perú, Magíster en Derechos Fundamentales - Area Sistema Interamericano de Protección por la Universidad Carlos III de Madrid, España; doctoranda en Derechos Fundamentales - Área Derecho Internacional Público por la Universidad Carlos III de Madrid, España; experta en sistemas regionales de protección, se desempeña como abogada de la Procuraduría Pública Especializada Supranacional - Ministerio de Justicia; consultora en género y Derechos Humanos, profesora de la Universidad Alas Peruanas y Universidad San Juan Bautista en las materias de Derechos Humanos, Jurisdicción Internacional, Derecho Internacional Público y Protección Internacional de los Derechos Humanos; Directora Nacional de la Liga Peruana Pro Derechos Humanos (Lipprodeh) y miembro del Movimiento Amplio de Mujeres.

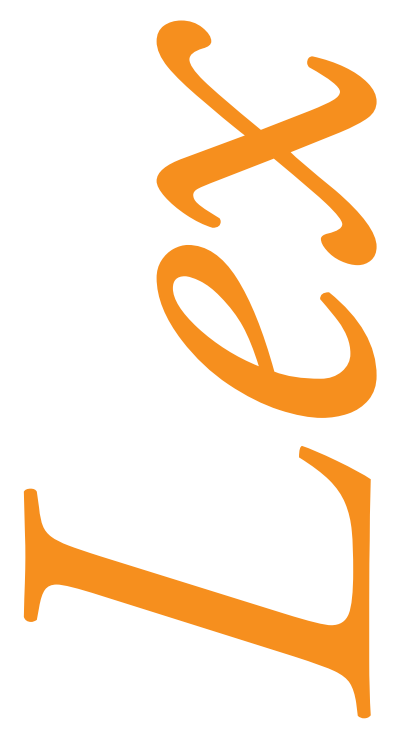




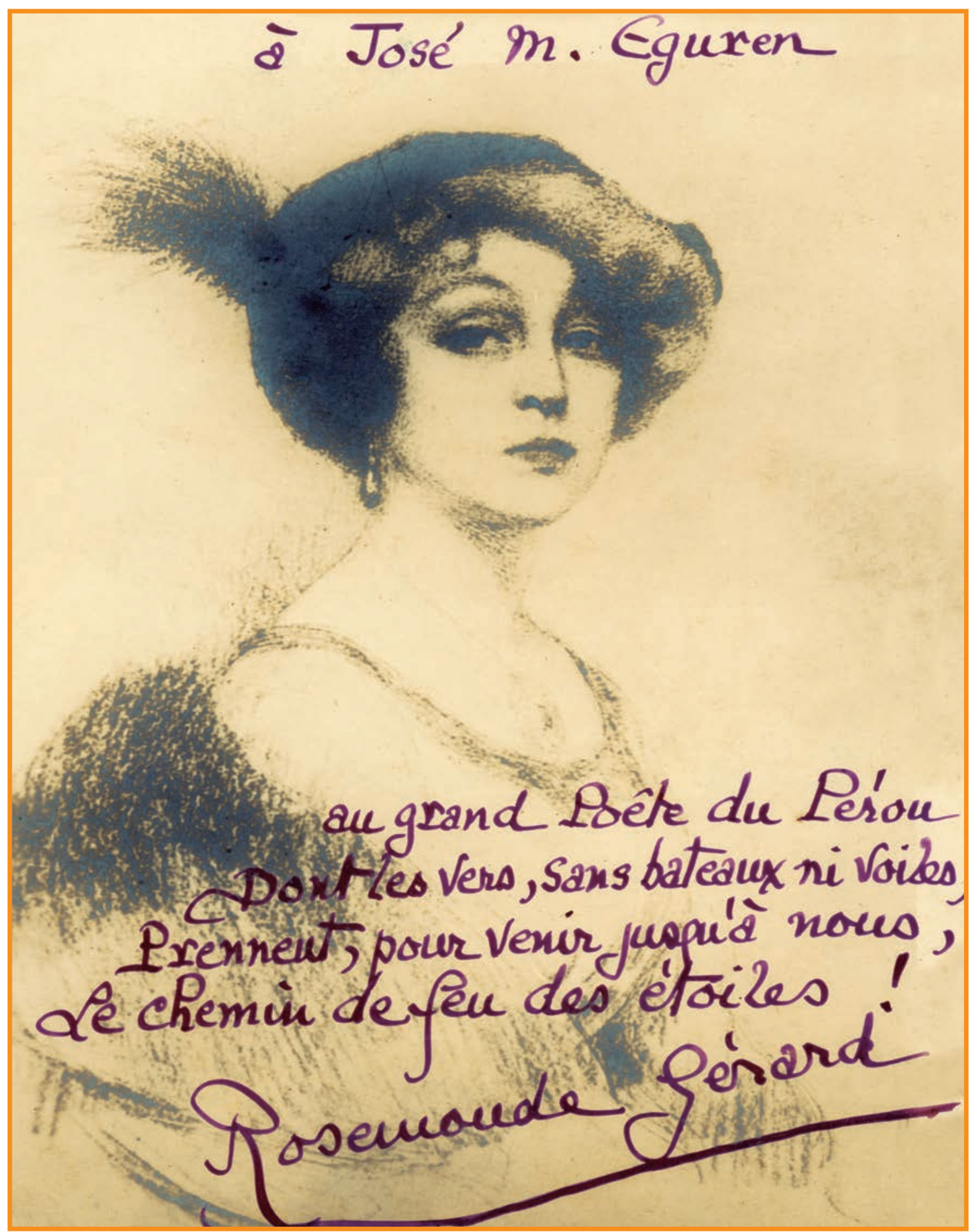

Poeta Francesa Rosedand Gerdal 


\section{Introducción}

El Preámbulo de la Carta de las Naciones Unidas de 1945 se abre con la afirmación hecha de que ellos están "resueltos (...) a reafirmar la fe en los derechos fundamentales del hombre, en la igualdad y el valor de la persona humana, en la igualdad de derechos de hombres y mujeres...". Desde entonces, muchos son los logros alcanzados y los fracasos en la búsqueda de eficaz protección internacional de tales valores y derechos. ${ }^{1}$

La Carta de las Naciones Unidas es el primer instrumento jurídico que, en forma clara e inequívoca, se refiere a la discriminación. La Comisión de la Condición Jurídica y Social de la Mujer creada en 1946 aseguró que se incluyeran previsiones sobre la igualdad de la mujer en la Declaración Universal de los Derechos Humanos, adoptada en 1948. En este sentido, el punto culminante lo constituyó la Carta UN de 1945 que constituye el primer tratado internacional de alcance universal que afirma solemnemente la fe en los derechos fundamentales de todos los seres humanos, en la dignidad y el valor de la persona humana. Así pues, el proceso de internacionalización de los Derechos Humanos se ha incrementado notablemente desde la adopción de la Carta UN. ${ }^{2}$ Esta comisión se creó para preparar "recomendaciones e informes sobre la promoción de los derechos de la mujer en las áreas política, económica, civil, social y educativa, y hacer recomendaciones sobre problemas urgentes en el área de los derechos de la mujer" ${ }^{3}$

Con la creación de la Comisión de Derechos Humanos y la Comisión de la Condición Jurídica y Social de la Mujer en 1946 y la adopción de la Declaración de los Derechos Humanos en 1948 comenzó el trabajo orientado a establecer las bases de la promoción de la igualdad de

MARIÑO MENENDEZ, Fernando. (edición). La Protección Internacional de los Derechos de la Mujer tras la Conferencia de Pekin de 1995.Universidad Carlos III de Madrid. Boletín Oficial del Estado. 9 pp.

VILLAN DURAND, Carlos. Curso de Derecho internacional de los derechos humanos, Editorial Trotta: Madrid, 2002, pp. $70-71$.

3 Comisión de la Condición Jurídica y Social de la Mujer. 
derechos para la mujer. El paso decisivo a la internacionalización definitiva de los Derechos Humanos en la Carta de 1945 cristaliza gracias a una serie de factores que concurrieron al final de la Segunda Guerra Mundial, como es el repudio contra los crímenes nazis, el deseo de paz, la afirmación de la supremacía de los valores democráticos, la re-fundación de la sociedad internacional organizada con la creación de la organización de las Naciones Unidas (ONU) y, sobre todo, la voluntad decidida de los Estados fundadores de la ONU en conseguir un consenso político que hiciera posible la construcción de un sistema universal de protección de los Derechos Humanos. ${ }^{4}$ En los Derechos Humanos, se producirá entonces un triple proceso de evolución: la positivización, la generalización y la internacionalización. ${ }^{5}$ Este efecto multiplicó los instrumentos a favor de la no discriminación contra la mujer en el mundo basados en la igualdad como principio fundamental.

El proceso de identificación de los derechos de la mujer tuvo que iniciarse en base a investigaciones sobre las discriminaciones existentes contra la mujer en la ley y los hechos. Los resultados de éstas, realizadas individualmente en los países, constituyeron el fundamento para los principios que fueron incorporados en el Derecho Internacional a través de tratados y convenciones. Como resultado de ello, en 1967, la Asamblea General adopta la Declaración sobre la Eliminación de la Discriminación contra la mujer. ${ }^{6}$

La proclamación en 1975 del Año Internacional de la Mujer y el compromiso, el mismo año, de la primera Conferencia Mundial del año Internacional de la Mujer, que se realizó en México, ayudó a movilizar a las mujeres de todo el mundo, expandiendo las relaciones entre Naciones Unidas y las Organizaciones No gubernamentales (ONG's) y diseminando los temas de igualdad, desarrollo y paz, como los básicos para ser desarrollados en los años siguientes. A partir de 1976, se produjeron importantes transformaciones en la interpretación del rol de la mujer. Estudios estadísticos, auspiciados y publicados por Naciones Unidas evidenciaban que la igualdad de derechos de la mujer influía definitivamente en el bienestar de la sociedad. Esta Convención es el primer tratado a nivel del Sistema Universal que define la discriminación contra la mujer. Es a través de esta norma internacional que los Estados deben generar políticas públicas para erradicar la discriminación del ámbito público y privado al interior de sus territorios.

4 VILLAN DURAN, Carlos. Curso de Derecho internacional de los derechos humanos, Editorial Trotta: Madrid, 2002., pág. 69.

PECES-BARBA, Gregorio. Derecho Positivo de los Derechos Humanos, Editorial Debate: Madrid 1987, pág. 13.

6 Aunque la Declaración no fue un instrumento jurídico vinculante, constituyó un paso importante en la formación de una base legal para la igualdad de derechos. 


\section{Los Derechos Humanos de las mujeres en el orden internacional}

El sistema de protección de los Derechos Humanos, tanto el universal como el interamericano, se fue desarrollando en forma lenta y progresiva como una conquista del individuo contra el Estado, que ha sido siempre el principal violador, lo que ha ido significando una limitación a su soberanía. ${ }^{7}$ Ignacio Ara Pinilla define los Derechos Humanos como las facultades que el hombre se atribuye como inherentes a su condición, reflejadas en el consenso social obtenido a partir de la realización de las exigencias de liberación de los condicionamientos que puedan sufrir la formación y la expresión de la voluntad de los individuos. ${ }^{8}$ En la actualidad, existe una cantidad de instrumentos jurídicos cuyo contenido está dirigido a proteger los derechos fundamentales de las personas y exigir la eficacia y vigor de los Estados en la aplicación de estos instrumentos, ya sean estos del sistema universal o en el sistema interamericano.

Sus principios han sido recogidos en las constituciones y ordenamientos jurídicos de numerosos Estados, y un gran número de tratados de Derechos Humanos se refieren a ella confirmando su innegable relevancia moral, política y jurídica. La declaración, por su carácter moral e importancia jurídica y política que ha adquirido con el transcurso del tiempo, constituye un hito en la lucha de la humanidad por la libertad y la dignidad a la altura de la Carta Magna inglesa, de la Declaración de Independencia americana y de la Declaración francesa de los Derechos del Hombre y del Ciudadano. ${ }^{9}$ La Declaración Universal supuso "una victoria (no total, ciertamente) de la humanidad entera". ${ }^{10}$ Una vez finalizada la II Guerra Mundial, la Comunidad Internacional fue testigo del fenómeno de universalización e internacionalización de los Derechos Humanos. Por otro lado, la creación de una cantidad de instrumentos internacionales ha permitido un desarrollo progresivo en la protección y promoción de los Derechos Humanos de las mujeres.

Esta defensa se afianzó universalmente cobrando importancia internacional a través de declaraciones, pactos y convenciones. En esta medida, queremos mostrar la implicancia universal y regional de la convención sobre la eliminación de todas las formas de discriminación contra la mujer, y cuál es el real sentido de encaminar y maximizar la importancia de los derechos contenidos en favor de las mujeres.

\footnotetext{
HITTERS, Juan Carlos. Derecho Internacional de los Derechos Humanos. Tomo I, Ediar: Buenos Aires, 1993, pág. 24.

8 ARA PINILLA, Ignacio. "Hacia una Definición Explicativa de los Derechos Humanos", en: Derechos y Libertades, Revista del Instituto Bartolomé de las Casas, Universidad Carlos III de Madrid, 1993, pág. 107.

CARRILLO Salcedo, JA. Soberanía de los Estados y Derechos Humanos en Derecho internacional contemporáneo. Madrid: Tecnos, 2001, pág. 18.

10 CASSESE, Antonio. Los derechos humanos en el mundo contemporáneo, Ariel: Barcelona, 1991, pág. 53.
} 
Es así que los Derechos Humanos de las mujeres están protegidos ahora por un extenso conjunto de leyes internacionales. ${ }^{11}$ Es importante resaltar que los derechos fundamentales son un concepto histórico del mundo moderno que surge progresivamente a partir del tránsito a la modernidad. Peces-Barba ${ }^{12}$ agrega:

Que la idea central, que podemos encontrar en todo momento histórico, será la de la dignidad humana. En esa línea, muchos instrumentos de los Derechos Humanos protegen específicamente los derechos humanos de las mujeres, tanto los Pactos Internacionales de Derechos Humanos, Derechos Civiles y Políticos, Derechos Económicos, Sociales y Culturales que resaltan el importante principio según el cual los gobiernos deben garantizar que las mujeres y los hombres tengan igual acceso a todos estos derechos.

Estos derechos, que fueron plasmados en la Convención sobre la Eliminación de todas las formas de Discriminación contra la Mujer - 1979 13 , incluyen todos estos derechos mencionados y el igual tratamiento ante la ley, pues la convención exige un trato igualitario para las mujeres y varones en las políticas de Estado y Gobierno. Obligando, además, a eliminar prácticas injustas basadas en prejuicios contra las mujeres en la esfera política, pública y privada, como la nacionalidad, educación, atención a la salud, empleo, matrimonio y relaciones familiares, se da prioridad al principio de igualdad jurídica y civil en atención al artículo 15 de esta convención.

Se debe tener presente que los Derechos Humanos emergen y erosionan como principio constitucional del Derecho Internacional. Pero no "desplazan" el viejo principio, también constitucional, de la soberanía de los Estados. Por lo que ambos principios constitucionales coexisten y se interrelacionan en una tensión dialéctica que debe tenerse muy presente para comprender las tensiones intrínsecas del Derecho Internacional de los Derechos Humanos en la fase actual de su evolución histórica.

11 Declaración Universal de Derechos Humanos; Pacto Internacional de Derechos Civiles y Políticos; Pacto Internacional de Derechos Económicos, Sociales y Culturales; Protocolo Facultativo de la Convención sobre la eliminación de todas las formas de discriminación contra la mujer; Protocolo Facultativo del Pacto Internacional de Derechos Civiles y Políticos; Protocolo adicional a la Convención Americana sobre Derechos Humanos en Materia de Derechos Económicos, Sociales y Culturales, "Protocolo de San Salvador"; Naciones Unidas, Consejo de Seguridad, Resolución 1325 del 2000; Convención Interamericana para prevenir, sancionar y erradicar la violencia contra la mujer "Convención de Belem Do Para"; Convención Americana Sobre Derechos Humanos "Pacto de San José de Costa Rica"; Convención sobre la eliminación de todas las formas de discriminación contra la mujer, Cuarta Conferencia Mundial Sobre La Mujer, Beijing; Declaración sobre la eliminación de la violencia contra la mujer, entre otros.

12 PECES BARBA, Gregorio. op.cit., pág. 11.

13 En adelante indistintamente la Convención o CEDAW. 
La convención es uno de estos instrumentos del sistema universal que coexisten con otras normas internacionales y se interrelacionan con los Estados en el rubro de la defensa de los derechos y la no discriminación de las mujeres a nivel interno dentro de los estándares internacionales. Con ello, obligan a todos aquellos países que suscribieron y ratificaron su compromiso en el diseño de políticas públicas a favor de las mujeres a modificar sus legislaciones e invertir, entre otras cosas, en la educación de sus pueblos, situación neurálgica que adolece nuestro país y otros estados.

El Perú ratificó esta convención ${ }^{14}$ con el compromiso de erradicar toda acción que viole los derechos y principios de igualdad de derechos y del respeto de la dignidad humana. Para ello, asumió la premisa de que todo Estado-parte en los Pactos Internacionales de Derechos Humanos tiene la obligación de garantizar su cumplimiento, y que todas las convenciones y declaraciones concertadas bajo el auspicios de la $\mathrm{ONU}^{15}$ y los organismos especializados tienen el deber de favorecer la igualdad de derechos entre hombres y mujeres. No obstante toda esta frondosa legislación internacional en la que el Perú suscribió esta convención con el compromiso de revalorar la participación de la mujer en la esfera política, social, económica y cultural para asegurar el pleno desarrollo y adelanto de la mujer en igualdad de condiciones ${ }^{16}$, las mujeres peruanas siguen siendo objeto de importantes discriminaciones. ${ }^{17}$

\subsection{Importancia de los instrumentos internacionales}

Podemos afirmar que los grandes avances en el campo de los derechos de las mujeres, por lo menos en cuanto a su formalización, están relacionados con la normatividad internacional sobre Derechos Humanos. ${ }^{18}$ Los textos de la Declaración Universal de los Derechos Humanos ${ }^{19}$, la

14 La convención sobre toda forma de discriminación contra la mujer (aprobada en 1979, abierta a la firma desde 1980 y en vigor desde 1981) tiene tantos Estados Partes como los Pactos sobre Derechos Civiles y Políticos y sobre Derechos Económicos, Sociales y Culturales. El texto del 1979 ha sido reforzado con la aprobación del Protocolo opcional al Convenio, adoptado por la Asamblea en diciembre de 1999. Ambos texto suponen el reconocimiento jurídico de las acciones positivas. Esta convención, en el caso del Perú, se suscribió el mes de julio de 1981 y fue ratificada por Perú el año de 1982.

15 La Asamblea General de la ONU redactó varias declaraciones posteriores a esos Pactos entre las que podemos citar las referidas: la discriminación contra la Mujer (1967), a los derechos del niño (1959), a los progresos y desarrollo en lo social (1969), a la erradicación del hambre.

16 Actualmente, se viene discutiendo a nivel del Congreso de la República en la "Comisión Especial revisora de la ley de protección frente a la violencia familiar", que busca penalizar la violencia contra la mujer. Significa poner fin a la violencia doméstica contra la mujer, y dar un mensaje a la sociedad en el que se condena la conducta del agresor (responsable de sus actos). Considero que no se trata de poblar las cárceles, me rehúso a esa realidad. Pero debemos empezar a la par a estas propuestas de reformas con una "campaña nacional" a todos los niveles, para "reeducar prácticas" que generan "violencia de género" para disuadir directamente a los violentadores y hacer cumplir la Convención.

17 Folleto Informativo No22, Discriminación contra la Mujer: La Convención y el Comité (Internet - CEDAW).

18 Naciones Unidas. "Avances Legales desde la aprobación de la Convención sobre la Eliminación de todas las formas de discriminación contra la mujer. Hacia la igualdad”, pág. 9.

19 René Cassin tuvo el acierto de sugerir, y su propuesta fue unánimemente aceptada, que el título de la declaración no 
Convención Americana de Derechos Humanos, el Pacto Internacional sobre Derechos Económicos, Sociales y Culturales, el Pacto Internacional sobre Derechos Civiles y Politicos y otros buscan referentes supranacionales con el suficiente consenso en la comunidad internacional como para obligar a los Estados a respetar los principios básicos de paz social, justicia y libertad que cimientan el de la dignidad humana. Es posible afirmar, sin temor a equivocarnos, que la defensa de los Derechos Humanos por parte de estos convenios internacionales considera que la dignidad humana deriva del respeto a los derechos de cada persona mediante el desarrollo armónico de su personalidad en el pleno ejercicio de la razón, en la toma de conciencia y, por consiguiente, en las relaciones intersubjetivas entre grupos humanos y entre sujetos individuales.

En ese sentido, los derechos de las mujeres han ido ganado espacio en la sociedad afirmando una protección legal (existe un catálogo de derechos) cuyo fundamento es la exigencia de materializar derechos naturales de las mujeres traducidos en políticas de promoción y protección de los derechos de las mujeres en el mundo. Este proceso tiene un consenso internacional relacionado a la incorporación de los principios de no discriminación y de igualdad entre los seres humanos.

La definición de discriminación es un punto de partida que permite juzgar tanto la discriminación de hecho, referida a situaciones concretas en las que se produce una pérdida de derechos para las mujeres, como son las desventajas sociales, como la discriminación de derecho contenida en los textos normativos, de los cuales se derivan distinciones que desfavorecen a las mujeres. ${ }^{20}$

En ese camino, hay importantes instrumentos internacionales relacionados a la vida de las mujeres, algunos de los cuales han sido suscritos y ratificados por el Perú. ${ }^{21}$ Todos estos convenios regulan relaciones jurídicas entre las mujeres, el Estado, las personas jurídicas de todo tipo y los sujetos individuales. La convención parte de la constatación, como circunstancia fundamental a tener en cuenta, de la condición oprimida de un grupo humano debido a una característica biológica que es el sexo y del reconocimiento de que la desigualdad real entre hombres y mujeres es un hecho lamentable en todas las sociedades del mundo.

fuese el de "Declaración Internacional", sino el de "Declaración Universal de Derechos Humanos". Con relación a los derechos económicos y sociales, la Declaración Universal expresa igualmente un consenso entre los bloques ideológicos enfrentados, enunció derechos civiles y políticos e incluyó también derechos económicos y sociales.

20 HENRIQUEZ, Narda y ALFARO, Rosa María. Mujeres, Violencia y Derechos Humanos. Los Derechos Humanos y los derechos de la mujer, IEPALA: Madrid, 1991.

21 La Convención sobre los Derechos Políticos de la Mujer, La Convención sobre la Eliminación de Todas las Formas de Discriminación contra la Mujer, y los Convenios OIT: No 45: Relativo al empleo de las mujeres en los trabajos subterráneos de toda clase de minas, entre otros. 
Mantiene, además, que sólo una vez corregidas, las discriminaciones por razón de sexo en sus diferentes aspectos, podrá hablarse de una verdadera consecución de la igualdad formal y real. Esta orientación es clara en la convención, cuyo texto no pone el énfasis en la delimitación y definición de los derechos de la mujer en sí, sino en la eliminación de las discriminaciones existentes contra ella. ${ }^{22}$

Cada vez más mujeres y hombres están entendiendo la necesidad de iniciar un proceso que, a partir de la denuncia colectiva de los derechos establecidos y vulnerados, permita la concientización de las múltiples formas de concebir los Derechos Humanos desde un punto de vista humanista. Cada vez más personas entienden que la reconceptualización de los Derechos Humanos requiere una reconceptualización de lo que entendemos por ser humanos. ${ }^{23}$

\subsection{Una convención distinta y especial para la mujer en el marco de Naciones Unidas}

Es importante preguntarnos, ¿por qué las Naciones Unidas adoptaron un tratado especial para la mujer?, entre algunas de las razones tenemos:

- Las mujeres en el mundo siguen sin tener derechos iguales a los de los hombres a pesar de la existencia de otros instrumentos.

- Siguen existiendo prácticas discriminatorias contra la mujer a nivel internacional en derechos políticos, civiles, derechos de familia, en los salarios a igual trabajo entre varones y mujeres.

- La discriminación obstaculiza el crecimiento económico y la prosperidad de las sociedades.

- Se busca que los Estados, a través de "la educación”, cambien de actitudes y superen los perjuicios y prácticas basados en funciones estereotipadas y así se logre la ansiada igualdad de derechos y obligaciones. ${ }^{24}$

22 BUSTELO GARCIA DEL REAL, Carlota. La Convención sobre la eliminación de todas las formas de discriminación contra la mujer. Garantía internacional de los derechos sociales: contribución de Naciones Unidas al progreso y desarrollo social, los derechos del niño, la eliminación de la discriminación de la mujer y desarrollo del Voluntariado. Ministerio de Asuntos Sociales: Madrid, 1990, pág. 214.

23 FACIO, Alda. "Repensamos como mujeres para reconceptualizar los Derechos Humanos", en: Género y Sociedad, 3,1. Centro de Estudios de Género del Instituto Tecnológico de Santo Domingo, 1995, pág.6.

24 Folleto Informativo No 22. "Discriminación Contra la Mujer: La Convención y el Comité." (Internet - CEDAW). 


\section{La convención sobre la eliminación de todas las formas de discriminación contra la mujer: en defensa de la igualdad}

El concepto de la protección de los derechos humanos se originó en el ámbito de la legislación interna con la Carta Magna de Inglaterra, conocida como Bill of Rights, de la Constitución de los Estados Unidos y la Declaración de los Derechos del Hombre en Francia. ${ }^{25}$ La ley de los Derechos Humanos aparece como un fenómeno. En el siglo XX, comenzó con la creación de la Organización de las Naciones Unidas y sus organismos en 1946. La misión de esta institución fue el fomento del respeto de los Derechos Humanos y de las libertades fundamentales.

Uno de los propósitos de las Naciones Unidas es realizar la cooperación internacional en la solución de problemas internacionales de carácter económico, social, cultural y humanitario, y en el desarrollo, sin hacer distinción por motivos de raza, sexo, idioma o religión, tal como establece el artículo dos de la Carta. ${ }^{26}$ A pesar de la amplia variedad de su contenido, la Declaración Universal fue proclamada como norma común de realización para todas las personas y todas las naciones, pero no fue redactada en forma de tratado que impusiera obligaciones contractuales a los Estados.

Esta tendencia orientó la creación de instrumentos jurídicos diversos y específicos como la "Convención sobre la eliminación de todas las formas de discriminación contra la mujer", considerada la Carta Magna de los Derechos Humanos de la Mujer. Esta orientación se produjo de tal forma que el énfasis se hizo sobre la definición de los derechos de la mujer en sí, con la finalidad de eliminar la discriminación contra ellas.

La Convención establece: que "los Estados Partes reconocerán a la mujer la igualdad ante la ley" ${ }^{27}$ y se "reconocerá en materias civiles, una capacidad jurídica idéntica a la del hombre y las mismas oportunidades para el ejercicio de esa capacidad, reconociendo también que los hombres y a las mujeres, tienen los mismos derechos con respecto a la legislación relativa al derecho de las personas a circular libremente y a la libertad para elegir su residencia y domicilio". ${ }^{28}$ El artículo 15 confirma la igualdad de la mujer ante la ley y exige a los Estados Partes que garanticen a la mujer el derecho a la igualdad con el hombre.

Desde la Conferencia Mundial de Copenhague se interpretó "la igualdad de derechos" como aquellas responsabilidades y oportunidades para la participación activa de las mujeres

25 PLATA, María Isabel y YANUZOVA, María (comp.) (1988). Los Derechos Humanos y la Convención sobre la eliminación de todas las formas de discriminación contra la mujer - 1979, Profamilia/ Fundación Ford: Bogotá, pág. 35.

26 Artículo 2 de la Declaración Universal de Derechos Humanos.

27 Artículo 15 de la Convención sobre la eliminación de todas las formas de discriminación contra la mujer.

28 Inciso 2, del artículo 15 de la Convención; op. cit. 
en el desarrollo como ciudadanas y así eliminar la discriminación de jure y materializar la igualdad ante la ley. La Convención es una declaración política que permite establecer, modificar, desarrollar o hacer cumplir una base jurídica lo suficientemente amplia, para lograr una igualdad de la mujer y del hombre fundada en la dignidad humana ${ }^{29}$ que sea reconocida culturalmente. La existencia de normas discriminatorias es en efecto una discriminación institucional y los Estados Partes quedan directamente obligados por la Convención a derogar estas disposiciones para abrir campo a la promulgación de nuevas leyes que son tan sólo un elemento de esta lucha por la igualdad, pero un elemento esencial es el cambio social que va más allá del cambio legislativo. ${ }^{30}$

Los Estados deben adoptar medidas especiales de carácter urgente para corregir el desequilibrio impuesto por siglos de discriminación contra la mujer y para acelerar la igualdad de facto entre hombres y mujeres ${ }^{31}$, eliminando los prejuicios y patrones socioculturales de conductas, en las relaciones de hombre y mujeres, dentro y fuera de la familia, en la sociedad en general. Lograr estos cambios es obligación de los Estados, modificando a través de políticas públicas, los patrones socioculturales. ${ }^{32}$ Son estas prácticas, las que deben ser reforzadas por los Estados a efectos de implementar la Convención, en busca de una erradicación de la discriminación contra la mujer de manera definitiva, de manera que trasluzca estas políticas públicas en el desarrollo de la sociedad y las familias.

\section{La eficacia de la Convención}

La convención sobre la eliminación de todas las formas de discriminación contra la mujer es un instrumento jurídico, internacionalmente decisivo, que exige respeto hacia los Derechos Humanos de la mujer y su observancia, siendo de alcance amplio, universal y de índole legalmente obligatoria. El objetivo de la Convención es el logro de la igualdad, entre hombres y mujeres, ante la ley ${ }^{33}$; el fin inmediato de la Convención es la eliminación de la discriminación ${ }^{34}$, busca la tutela internacional de los Derechos Humanos de las mujeres. ${ }^{35}$

La eficacia de esta está dentro del contexto del sistema internacional de protección de los derechos humanos. Está basada en la idea de que la persona humana tiene derechos

29 La formación de esta amplia base jurídica comprende la abolición de normas discriminatorias, la modificación de otras que no se ajustan a las exigencias legales de la Convención y desde luego, la promulgación de leyes para impulsar los nuevos procesos de integración de la mujer en el desarrollo material y espiritual.

30 PLATA, María Isabel y YANUZOVA, op. cit. 38 pp.

31 El "derecho a la igualdad ante la ley sin discriminación" se encuentra en el artículo 7 de la Declaración Universal de los Derechos Humanos de la ONU constituyéndose en uno de los elementos del derecho a la no discriminación consagrado.

32 PLATA, María Isabel y YANUZOVA, María, op. cit., pág.71.

33 Artículo 11 de la Convención sobre la eliminación de todas las formas de discriminación contra la mujer.

34 Artículo 12 de la Convención, op. cit.

35 Op.Cit., pág. 161. 
provenientes de su dignidad y humanidad que tienen que ser puestos a salvo frente a aparatos estatales despóticos. Esta circunstancia determina la importancia de la norma internacional y la manera cómo cada uno de los Estados soberanos debe proteger a la persona humana en el área del derecho internacional.

La obligación asumida por los Estados, en virtud de este instrumento internacional, es la de garantizar o la de ofrecer a sus ciudadanas, los derechos estipulados en el tratado. ${ }^{36}$ Con este propósito final, aceptan otras obligaciones que se desprenden del contenido del art. 24. "Los Estados Partes condenan la discriminación contra la mujer en todas las formas, convienen en seguir, por todos los medios apropiados y sin dilaciones, una política encaminada a eliminar la discriminación contra la mujer" ${ }^{37}$ Comprometiéndose a seguir, por todos los medios apropiados y sin dilación, una política encaminada a eliminar la discriminación contra la mujer ${ }^{38}$, comprometiéndose en la búsqueda o realización de políticas que proveerán el contenido normativo de la obligación de "condenar".

Los Estados deben darle reconocimiento legal a las obligaciones adquiridas bajo la Convención y además deben crear los medios legales a través de los cuales las mujeres pueden reclamar sus derechos. La obligación que asumen los Estados, al ratificar, es en realidad la de trazar, construir y ejecutar una política que no se reduzca simplemente a una política legislativa. El compromiso internacional que han adquirido los Estados consiste en la toma de una serie de numerosas medidas progresivas, legislativas y de cualquier otra índole que, en conjunto, van a constituirse en garantía para la igualdad de facto entre hombres y mujeres en el goce y ejercicio de los derechos humanos. ${ }^{39}$

\section{Conclusiones}

Esta Convención pertenece al Sistema Universal de Protección y Promoción de los Derechos de las Mujeres, y busca erradicar la discriminación contra la mujer a nivel mundial bajo el respaldo de principios que rigen el derecho internacional como el erga omnes, o el pacta sunt servanda que obliga a los Estados a adecuar sus legislaciones internas a los estándares internacionales y efectivizar sus compromisos internacionales.

Todo Estado Parte que haya suscrito esta Convención tiene la obligación de garantizar su cumplimiento, así como todas las convenciones y declaraciones concertadas bajo el auspicio de la ONU y los organismos especializados tienen el deber de favorecer la igualdad de derechos

Artículo 24, op. cit.

Artículo 2, op. cit.

Artículo 16, op. cit.

Artículo 4, op. cit. 
entre hombres y mujeres. Los Estados tienen la obligación específica y concreta de cumplir con los compromisos que asumen debiendo promover, mediante la enseñanza y la educación, el respeto a los derechos y libertades en todas sus naciones y el respeto universal y efectivo de los derechos y libertades humanas.

Los Estados están obligados a dictar las disposiciones legales que fueren necesarias para hacer efectivos los Derechos Humanos. Esta Convención complementa adecuadamente todos los dispositivos generales sobre Derechos Humanos y debería ser ampliamente difundida y comentada. Cada ciudadana debería conocer el contenido de esta normatividad para aplicarla en su vida diaria. De la misma manera, los grupos de mujeres en la defensa legal deberían apelar a artículos específicos a fin de influir en los criterios judiciales, cuando está en conflicto el reconocimiento de sus derechos.

\section{Conclusiones}

- ARA PINILLA, Ignacio. "Hacia una Definición Explicativa de los Derechos Humanos, Derechos y Libertades”, en: Revista del Instituto Bartolomé de las Casas, Universidad Carlos III: Madrid, 1993.

- BALlESTEROS, Jesús (ed.). Derechos humanos: concepto, fundamento, sujetos, Tecnos: Madrid, 1992.

- BUSTELO GARCIA DEL REAL, Carlota. "La Convención sobre la eliminación de todas las formas de discriminación contra la mujer”. Garantía internacional de los derechos sociales.- contribución de Naciones Unidas al progreso y desarrollo social, los derechos del niño, la eliminación de la discriminación de la mujer y desarrollo del Voluntariado. Ministerio de Asuntos Sociales: Madrid, 1990.

- CARRILLO SALCEDO, Juan Antonio, Soberanía de los Estados y derechos humanos en el Derecho internacional contemporáneo. Tecnos: Madrid, 2001.

- CASSESE, Antonio. Los derechos humanos en el mundo contemporáneo, Ariel: Barcelona, 1991.

- Convención sobre la Eliminación de todas las formas de Discriminación contra la Mujer, a. G.res. 34/180,34 u.n. gaor supp. (No 46) p. 193, ONU doc. a/34/46, entrada en vigor 3 de septiembre de 1981.( Internet).

- Convenio OIT No 45: Relativo al empleo de las mujeres en los trabajos subterráneos de toda clase de minas. 
- Convenio OIT No 111: Relativo a la discriminación en materia de empleo y ocupación.

- Curso de Derecho Internacional. Comité Jurídico Interamericano. XXV, 1998.

- Declaración Universal de Derechos Humanos

- FACIO, Alda. "Repensamos como mujeres para reconceptualizar los Derechos Humanos", en: Género y Sociedad, 3,1 Centro de Estudios de Género del Instituto Tecnológico de Santo Domingo, 1995.

- Discriminación contra la Mujer: La Convención y el Comité, (Internet - CEDAW), Folleto Informativo No22.

- GOZAINI, Osvaldo Alfredo. El Proceso Transnacional. Particularidades Procesales de la Corte Interamericana de Derechos Humanos, Editorial Ediar: Buenos Aires/Argentina, 1992.

- GUZMAN, Laura (1996), "IV Conferencia Mundial sobre la Mujer: Interrogantes, nudos, y desafíos sobre el adelanto de las mujeres en un contexto de cambio", en: Estudios Básicos de Derechos Humanos IV, Instituto Interamericano de Derechos Humanos: San José de Costa Rica.

- HITTERS, Juan Carlos. Derecho Internacional de los Derechos Humanos, Tomo I. Ediar: Buenos Aires, 1993.

- HENRIQUEZ, Narda y ALFARO, Rosa María. Mujeres, Violencia y Derechos Humanos. Los Derechos Humanos y los derechos de la mujer, Iepala: Madrid, 1991.

- La Mujer en el mundo de hoy. Situaciones y políticas de los Gobiernos. Pekin 1995, Escuela Libre Editorial: Madrid, 1997.

- Naciones Unidas. Avances Legales desde la aprobación de la Convención sobre la Eliminación de todas las formas de discriminación contra la mujer. Hacia la igualdad.

- Pacto Internacional de Derechos Civiles y Politicos

- PECES-BARBA, Gregorio. Derecho Positivo de los Derechos Humanos. Editorial Debate: Madrid, 1987.

- PLATA, María Isabel y YANUZOVA, María (comp.). Los Derechos Humanos y la Convención sobre la eliminación de todas las formas de discriminación contra la mujer - 1979, Profamilia/ Fundación Ford: Bogotá, 1988. 
- Protocolo Facultativo de la Convención sobre la Eliminación de todas las formas de Discriminación contra la mujer. (Internet).

- MARIÑO MENENDEZ, Fernando M. La Protección Internacional de los Derechos de la Mujer tras la Conferencia de Pekin de 1995, Universidad Carlos III de Madrid: Madrid, Boletín Oficial del Estado.

- VILLAN DURAND, Carlos, Curso de Derecho internacional de los derechos humanos, Madrid, Editorial: Trotta, 2002. 


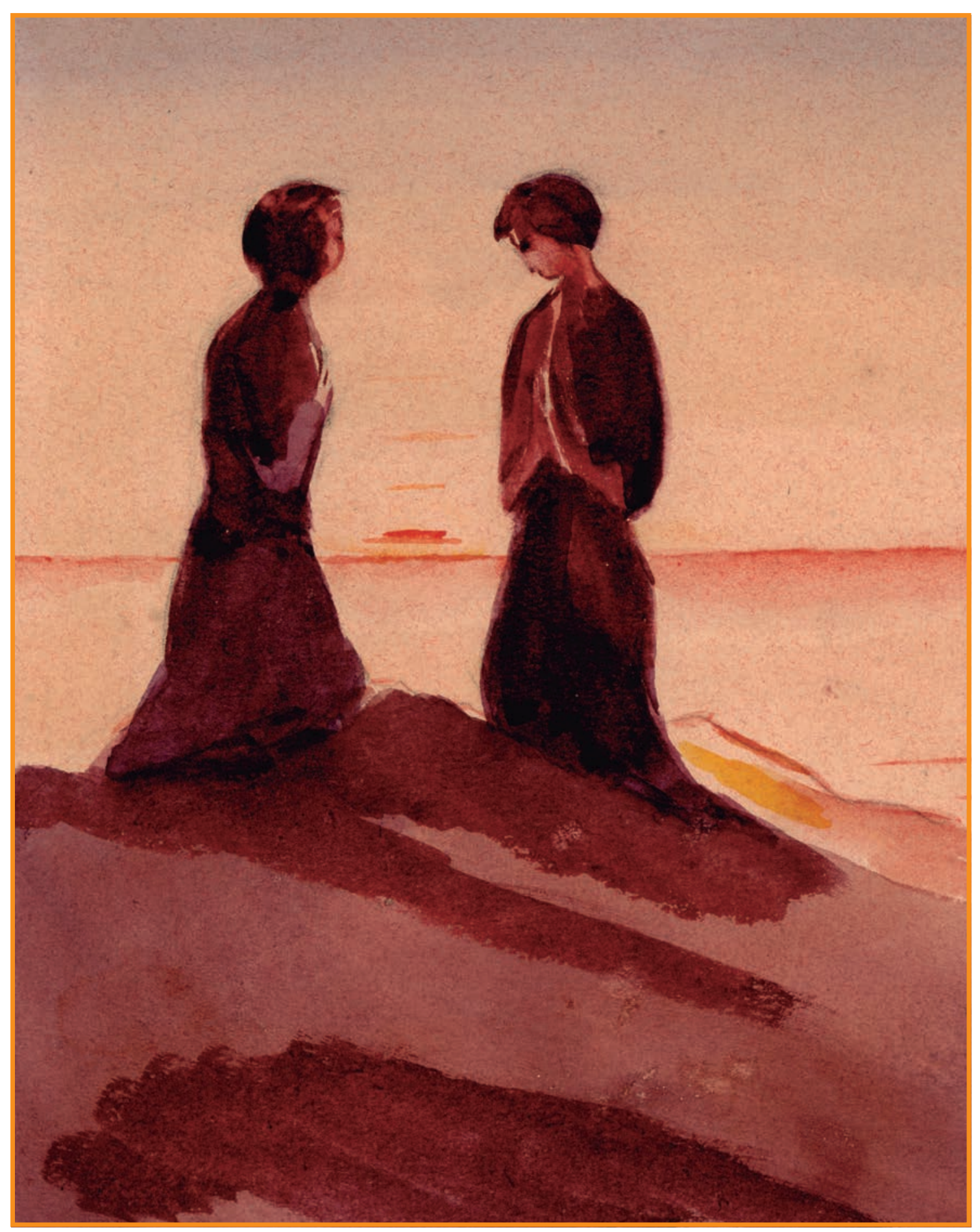

Oración de la tarde 